\title{
ИННОВАЦИИ И КОНКУРЕНТОСПОСОБНОСТЬ ПРЕДПРИЯТИЯ
}

\section{Н. П. Четырбок ${ }^{1}$}

${ }^{1}$ К. э. н., доцент, заведующий кафедрой управления, экономики и финансов учреждения образования «Брестский государственный технический университет», Брест, Беларусь, e-mail: natabrest@hotmail.com

\section{Peсрерат}

В современных условиях конкурентоспособность стала одной из основополагающих идей при разработке экономической политики любого субъекта рыночных отношений. В условиях постоянно усиливающейся конкуренции рост добавленной стоимости в выпуске продукции возможен только при наличии у предприятия компетентных преимуществ, формируемых путем внедрения в производственные процессы инновационных технологий и техники. При этом инновационная деятельности должна быть направлена: на снижения затрат и повышение качества продукции, внедрение эффективных методов управления, разработку инновационной стратегии развития и рост креативного потенциала предприятия.

Ключевые слова: инновационная деятельность, конкурентоспособность, эфффективная монополия, инновационная стратегия, конкурентные преимущества.

\section{INNOVATION AND ENTERPRISE COMPETITIVENESS}

\section{Abstract}

\section{N. P. Chetyrbock}

In modern conditions, competitiveness has become one of the fundamental ideas in the development of economic policy of any subject of market relations. In the conditions of constantly increasing competition, the growth of added value in the output of products is possible only if the enterprise has competent advantages formed by the introduction of innovative technologies and equipment into the production processes. At the same time, innovative activities should be aimed at: reducing costs and improving the quality of products, introducing effective management methods, developing an innovative development strategy and increasing the creative potential of the enterprise.

Keywords: innovation activity, competitiveness, effective monopoly, innovation strategy, competitive advantages.

\section{Введение}

В современном мире конкурентоспособность стала одной из основополагающих идей в разработке экономической политики. Она служит всеохватывающим понятием в дискуссиях по вопросу о том, как улучшить функционирование экономики. Но какие факторы для этого необходимо задействовать и какие ресурсы привлечь? Изучим этот вопрос подробнее.

\section{Инновации и конкурентоспособность}

В документах Европейской Экономической Комиссии ООН, посвященных вопросу конкурентоспособности в современной экономике, она рассматриваться как в «узком», так и в «широком» аспекте. В первом случае упор делается на способности национальных компаний вести конкурентную борьбу на мировых рынках и оцениваются стоимостные показатели и внешние параметры экономической динамики. Во втором - на факторах, влияющих на производительность труда, и в конечном итоге на движущих силах экономического роста $[1$, р. 6]. В исследуемом контексте нас интересует именно "узкий» аспект.

В случае, когда компании рассматриваются в качестве конечных носителей конкурентоспособности, становится очевидным, что их конкурентный потенциал растет не только за счет снижения издержек, но и за счет освоения производства новых товаров и услуг повышения уровня их качества, диверсификации и технической сложности изделий, имеющих более высокую добавленную стоимость. И здесь уже проводится прямая корреляция уровня их конкурентоспособности с инновационной деятельностью, которая может позволить им не только сохранить или повысить свою долю на внутреннем рынке, но и проникнуть на внешние.

Последнее означает, что в совокупном объеме корпоративных продаж повышается доля экспорта. Тогда в качестве показателя конкурентоспособности страны может использоваться динамика изменения структуры торгового баланса, происходящая за счет роста экспортных рынков. При этом конкурентоспособность страны на мировых рынках будет рассматриваться как результат агрегирования международной конкурентоспособности ее экспортоориентированных компаний [1, р. 7].
Концепция конкурентоспособности часто переплетается с кониепцией инновационной деятельности, которая рассматривается как один из важнейших источников конкурентных преимуществ и экономического динамизма, особенно в условиях стремительно меняющегося мира, где технологический прогресс и либерализация торговли привели к расширению масштабов экономического взаимодействия. Факторы же, положительно влияющие на способность компаний вести конкурентную борьбу, во многом совпадают с теми фракторами, которые были определены в качестве благоприятствующих инновационной деятельности [1, р. 4].

Поэтому инновационная деятельность рассматривается как главная движущая сила конкурентоспособности в рыночной экономике. Это обусловлено тем, что структурные изменения, направленные на переориентацию экономики на более эфффективные модели производства с более высокой технологической составляющей и добавленной стоимостью, как правило, связаны с повышением конкурентоспособности, формирующейся в результате реализации инновационной деятельности. В документах $\mathrm{OOH}$, в частности, отмечается: «Там, где давление конкуренции в пользу инноваций отсутствует, владение долей на рынке вполне может стать фактором воздействия на него и приносить монопольную ренту, не оказывая положительного влияния на экономический рост» [1, р. 13,28; 2, с. 94].

Приняв в качестве исходных заключения, сделанные экспертами Европейской экономической комиссии, проведем анализ инновационных фракторов, определяющих уровень конкурентоспособности производственных предприятий.

Для начала определимся с тезисом об инновационной деятельности, как главной движущей силе конкурентоспособности в рыночной экономике. Если исходить из современных представлений о роли инноваций в экономическом развитии, то можно вполне определенно утверждать, что от того, насколько успешными будут результаты инновационной деятельности, зависит конкурентоспособность компании на занимаемом ею сегменте рынка. Не секрет, что благодаря внедрению инноваций происходит обновление производственной базы предприятия на основе использования энергоэффрективных, низкозатратных, наукоемких технологий, применения более дешевых, устойчивых к внешним воздействиям, экологически чистых 
видов сырья. В результате повышается качество и снижается себестоимость производимых изделий, улучшаются их потребительские характеристики и расширяется ассортимент. Всё это прямые аргументы в пользу роста конкурентоспособности выпускаемой продукции, которая оценивается в первую очередь с точки зрения ее цены, качества и соответствия потребительских характеристик покупательским предпочтениям.

Однако влияние научно-технического прогресса на эти процессь носит более многофракторный характер. Оно происходит путем изменения самого содержания конкурентных отношений, усиления воздействия на рыночный спрос, возрастания значимости функциональных (организационно-управленческих) инноваций. Акценть в конкурентной борьбе хозяйствующих субъектов все больше смещаются с ценовой области в область технологии производства, новизны и совершенствования выпускаемой продукции. Главной целью выпуска новых или обновленных товаров становится борьба за покупательские предпочтения [3].

В то же время вести конкурентную борьбу в таком широком диапазоне в состоянии только крупные корпорации, имеющие достаточные для этого финансовые средства и научно-технический потенциал, необходимые для реализации дорогостоящих инновационных проектов. Затраты на инновационную деятельность, захватывающую научную фазу инновационного цикла, способны окупаться только при использовании эффректа масштаба, что не доступно малому и среднему бизнесу. Крупные же компании в этом случае на какое-то время становятся технологическими монополистами и могут получать инновационную ренту.

Этот особый тип монополии Й. Шумпетер назвал эффективным, так как он предполагает активную конкуренцию, когда стремление к монополизации рынка основано на повышении эффеективности производства. При этом такая монополия и получаемая в результате использования преимуществ от ее реализации сверхприбыль преходящи. Они не могут существовать долговременно и исчезают по той же причине, что и появились - в результате идущих им на смену инноваций нового поколения (Шумпетер, Гэлбрейт, 2021).

С этой целью предприятие, осуществляющее инновационную деятельность, строит свой бизнес-процесс на следующих основных подходах:

- снижение затрат и повышение качества продукции путем внедрения достижений научно-технического прогресса;

- использование эффрективных методов управления;

- следование инновационной стратегии развития;

- повышение квалификации и мотивация сотрудников.

Рассмотрим, как реализуются эти направления деятельности и как они влияют на конкурентоспособность компании

1. Способность предприятия стимулировать спрос за счет ценового фактора напрямую зависит от доли добавленной стоимости в выпуске производимой им продукции. Чем она выше, тем больше у него возможностей манипулировать процессом ценообразования, включая использование механизма демпинга Снижение доли промежуточного потребления происходит в результате снижения издержек производства, что, в свою очередь, детерминируется внедрением ресурсосберегающих технологий и снижением условно постоянных затрат.

В первом случае положительный результат может быть получен за счет применения продуктовых или процессных инноваций, во втором - организационно-управленческих (использования энергопотребляющего оборудования пониженной мощности, оптимизации структуры управления, разработки проектной документации и введения в эксплуатацию собственных производственных и офисных площадей взамен арендных, использования современных методов внутренней логистики и др.). Но суть остается одна - ценовой фрактор роста конкурентоспособности компании может быть использован только в результате инновационной деятельности.

В том, что касается качества продукции, то оно определяется ее дизайном, конструктивными особенностями, способными стать конкурентными преимуществами, долговечностью, бесперебойностью работы. Данные характеристики обеспечиваются уровнем конструкторских разработок, эфффективностью используемых технологий, применяемых в основном производстве, видом используемого сырья, наличием системы менеджмента качества. Очевидно, что в их основе лежат производственнье и функциональные инновации, что не требует специальных доказательств.

Технические характеристики изделия напрямую зависят от технологической укладности (ТУ) производства. Если в нем активно используются достижения микроэлектроники (VTУ) или нанотехнологии (VITY), то такое изделие может быть отнесено к высокотехнологичным и способно удовлетворить спрос как промышленных предприятий, так и покупателей товаров бытового назначения.

2. Эффективными методами управления в рассматриваемом контексте могут считаться те, которые организуют и стимулируют инновационную деятельностью на предприятии, поскольку ее целевой функцией является рост его интегральной конкурентоспособности. Согласно [5, с. 325] к ним относятся:

- проведение исследований и разработок;

- инновационное проектирование;

- инвестирование инновационной деятельности;

- коммерциализация объектов интеллектуальной собственности.

Проведение исследований и разработок (ИР) предприятием обусловлено только одной причиной - стремлением к лидерству на рынке. Лидерство обеспечивает увеличение масштабов производства, расширение географии продаж, рост добавленной стоимости в выпуске продукции. При этом оно само обеспечивается наличием у компании конкурентных преимуществ, фоормирование которых происходит только в результате инновационной деятельности, что, на наш взгляд, достаточно аксиоматично.

Речь здесь идет о том, что каждая продукция имеет определенное значение наукоемкости, показатель которой выражается через процентное соотношение затрат на ИР, произведенных предприятием, и добавленной стоимости, созданной им в расчетный период. Величина этого соотношения должна быть ориентирована на среднестатистические значения наукоемкости продукции, выпускаемой в отрасли. По данным [6, с. 9] они могут существенно разниться в зависимости от сложности и уровня технологичности базовых производств последней. Например:

- вычислительная техника - $12 \%$;

- фармация - $10 \%$;

- микроэлектроника - $7.5 \%$;

- приборостроение - 6,5\%;

- связь и энергетика - $6 \%$;

- лесное хозяйство - $2 \%$;

- легкая и пищевая промышленность - 0,5\%.

Очевидно, что когда компания стремится к лидерству, размер ее затрат на ИР должен обеспечивать ей уровень наукоемкости производимой продукции как минимум выше среднего по отрасли, а в случае экспортной ориентации и среднемирового. Ведь для того, чтобы выйти на новые рынки и утвердиться на них со своим брендом, нужно быть на голову выше конкурентов, а гарантию этого могут дать только радикальные инновации. Можно, конечно, пойти и по пути демпинга, но для этого также необходимо иметь крайне низкую себестоимость продукции, что также достигается только в результате инновационной деятельности.

Существует еще один аспект, влияющий на размер затрат, осуществляемых компанией на ИР. Это выбранная ею стратегия развития. Если исходить из стратегических альтернатив развития Л. Раменского - Х. Фризевинкеля [7, с. 64], то у предприятий-виолентов в условиях неизменных конкурентных отношений(при наличии картельного сговора) инновационная активность и, соответственно, расходы на ИР находятся на достаточно низком уровне. Предложение новых товаров на рынке в этом случае имитируется ими путем изменения дизайна уже выпускаемой продукции или использованием в ней дополнительных опций, не требующих радикальных изменений в технологии производства.

Предприятия-патиенты, ориентированные на производство эксклюзивной качественной продукции с высокой потребительской ценностью и уровнем сервисного обслуживания, уже в силу выбранной ими стратегии вынуждены поддерживать расходы на ИР на среднем уровне, характерном для трансформационных инноваций с наукоемкостью, находящейся в пределах $3,5-8,5 \%$ [6, с. 10].

Предприятия-эксплеренты по сути являются малыми инновационными предприятиями, деятельность которых направлена главным образом на создание и производство инновационного продукта, 
Вестник Брестского государственного технического университета. 2021

включая проведение научных исследований и разработок. Согласно белорусскому законодательству, к ним относятся те предприятия, у которых доля продукции старше трех лет в общем объеме выпускаемой продукции составляет не более $10 \%$. Их практические интересы лежат в завоевании определенного сектора на рынке научнотехнической продукции, что позволяет им внедрять свои разработки в мелко-серийное производство нестандартной, наукоемкой продукции с невысокой капиталоемкостью. Их расходы на ИР относятся к высоким.

Таким образом ИР, проводимые предприятием, становятся залогом его успешности на конкурентных рынках.

Структурно ИР, наряду с монтажом и пусконаладкой, относятся к инвестиционной фазе инновационного проекта, по итогам которого начинается производство конечной инновационной продукции [6, с. 14]. Таким образом, инновационный проект не только объединяет в себе все фазы инновационного цикла, но и интегрально решает задачу обеспечения лидерства компании на конкурентном рынке. Этому способствует проводимый в его рамках расширенный маркетинг, главной задачей которого становится не просто анализ конъюнктуры рынка, а разработка конкурентной стратегии развития компании. Для этого осуществляется постоянный мониторинг институциональных изменений, происходящих во внешней среде исследуется спрос на новый продукт, ведется поиск перспективных сегментов рынка, анализируются возможные направления развития отрасли, изучаются сильные и слабые стороны основных конкурентов, вырабатывается ценовая политика по реализации новой продукции. Такой подход позволяет выявить внешние для предприятия вызовы с тем, чтобы затем научно обоснованным образом подойти к формированию его конкурентного потенциала.

Для этих целей может использоваться STEP-анализ - маркетинговый инструмент, предназначенный для определения социальных (Social), технологических (Tech-nological), экономических (Economical) и политических (Political) групп факторов, влияющих силой своего воздействия на развитие компании. В равной мере к ним можно отнести рыночные, конкурентные и иные факторы.

Для обобщения результатов исследования может применяться уже SWOT-анализ, выполняемый матричным методом (таблица 1).

Таблица 1 - Матрица SWOT-анализа

\begin{tabular}{|l|l|}
\hline S (strenght) - & O (opportunaties) - \\
Сильные стороны предприятия & Рыночные возможности \\
\hline W (weakness) - & T (threats) - \\
Слабые стороны предприятия & Внешние вызовы \\
\hline
\end{tabular}

В нем складываются в единое целое конкурентный потенциал компании и результаты STEP-анализа, что позволяет в первом приближении определить место компании на рынке и перспективы ее дальнейшего развития. В геометрии данной матрицы вертикаль «S-W» (левый столбец) характеризует компанию, а столбец «O-T» рынок. Горизонталь «S-O» отражает сильные стороны предприятия на рынке, a «W-T» - его слабые стороны и потенциальные внешние угрозы.

Такой вид маркетинга получил название инновационного, а его главной доминантой является конкурентная направленность исследования.

В том, что касается инвестиций, то их целесообразность можно расценивать как своего рода «осознанную необходимость». При этом их эффрективность может существенно различаться, достигая своего максимума при финансировании инновационной деятельности. Очевидно, что чем выше капиталоотдача, тем устойчивее положение предприятия на рынке и тем выше уровень его конкурентоспособности. Это не требует отдельных доказательств и именно поэтому макрорегулятор предоставляет значительные льготы предприятиям осуществляющим инновационную деятельность, увеличивая и без того высокую доходность капитала, изначально обусловленную ростом производительности труда при инвестициях в основной капитал, создаваемый в процессе реализации инновационных проектов. При инвестировании инновационной деятельности возможно и общее снижение затрат благодаря бюджетным субсидиям и грантам, налоговым льготам и таможенным преференциям, представляемым инновационно активным предприятиям, а также использованию ими более дешевых финансовых ресурсов и ваучеров, выделяемых инновационными фондами на определенных стадиях инновационного цикла [8, с. 14].

Еще одним конкурентоориентированным методом управления инновационной деятельностью на предприятии является коммерциализация объектов интеллектуальной собственности (ОИС). Рассмотрим какие конкурентные преимущества получает предприятие в результате реализации этих процессов. Во-первых, если оно собирается использовать права на ОИС в собственном производстве, то производимая на их основе продукция должна быть запатентована, так как отсутствие патента снижает стоимость продаж продукции до 30 \% по сравнению с аналогом, имеющим патентную защиту. Кроме того реализация непатентованной продукции за рубеж вместо прибыли вообще может принести одни убытки [6, с. 27]. Во-вторых, в случае передачи прав на использование ОИС сторонней организации по договору лицензии или коммерческой концессии предприятие фрактически расширяет свои рынки сбыта и приобретает вместо потенциальных конкурентов зависимых от него партнеров по бизнесу.

3. Необходимость разработки и следования инновационной стратегии развития лучше всех сформулировал родоначальник концепции стратегического менеджмента И. Ансофф. По его мнению, инновационная стратегия приобретает особое значение вследствие зависимости конкурентоспособности и выживаемости предприятия от его способности к перманентному обновлению [6, с. 27].Таким образом, она становиться важнейшим элементом общей стратегии компании, связывающим инновационный потенциал последней с основными приоритетами её развития.

Но дело здесь не только в точке зрения известного ученого, необходимо понимать, что собственно алгоритм разработки инновационной стратегии включает в себе анализ внутренних и внешних фракторов влияния, прогноз научно-технического развития предприятия в рамках его отраслевой принадлежности, а также выявление стратегических направлений его инновационного развития и соответствующие им механизмы обеспечения поставленных целей [6, с. 76]. В результате он образует органическое единство с рассмотренной выше маркетинговой конкурентной стратегией развития компании.

4. Последний аспект влияния инновационной деятельности на конкурентоспособность предприятия касается способности его сотрудников креативно относится к выполнению своих служебных обязанностей, так как сегодня не просто хорошая квалификационная подготовка и богатый профессиональный опыт работников являются определяющим условием инновационной ориентации предприятия и, как следствие, роста его конкурентоспособности, а уровень проявляемой ими творческой инициативы, способности к созидательной деятельности при выполнении своих функциональных обязанностей [10].

То есть сотрудник должен быть способен решать не только предметно-ориентированные, но и проблемно-ориентированные задачи. И от этого будет зависеть - сможет ли предприятие внедрять в практику своей производственной деятельности научнотехнические достижения, способные кардинально повысить производительность труда, использовать для этого эфффективные методы управления, разрабатывать и следовать инновационной стратегии развития.

Креативность мышления позволяет индивиду генерировать новые идеи и формулировать перспективные цели, разрабатывать ранее не известные пути их достижения. Она представляет собой альтернативу шаблонности, отличающейся ограниченностью в выборе нестандартных решений задач, возникающих в производственной деятельности предприятия. Это подтверждает тот фракт, что успех использования инноваций на 85-90 \% зависит от инновационной подготовки персонала [6, с. 59; 11, с. 94,95].

Таким образом, можно констатировать, что конкурентоспособность любого хозяйствующего субъекта фрункционально обусловлена уровнем креативного потенциала его персонала.

\section{Заключение}

На основании проведенного исследования можно сделать следующие обобщающие выводы: 
1. По данным ООН инновационная деятельность сегодня является главной движущей силой конкурентоспособности в рыночной экономике.

2. Исследования подтверждают, что формирование конкурентных преимуществ компании происходит только в результате осуществления инновационной деятельности

3. К инновационным видам деятельности на предприятии, напрямую влияющим на рост его конкурентного потенциала относятся:

- внедрение ресурсосберегающих, энергоэффективных технологий;

- повышение технологического уклада производства;

- $\quad$ проведение научных исследований;

- выполнение инновационных проектов;

- инвестирование инновационной деятельности;

- коммерциализация объектов интеллектуальной собственности;

- $\quad$ разработка и следование инновационной стратегии развития;

- $\quad$ повышение креативного потенциала сотрудников.

\section{Список цитированных источников}

1. Ансофф, И. Стратегический менеджмент. Классическое издание И. Ансоффф. - СПб.: Питер, 2011. - 344 с.

2. Головачев, А. С. Формирование конкурентных стратегий развития предприятий. Экономика и управление / А. С. Головачев, М. А. Головачева. - № 2. - 2011. - С. 61-67.

3. Защита монополии в теориях И. Шумпетера и Д. К. Гэлбрейта [Электронный ресурc]. - Режим доступа: https://economyweb.org/?p=98. - Дата доступа: 20.02.2021.

4. Инновационность как фактор конкурентоспособности [Электронный ресурс]. - Режим доступа: https://infopedia.su/8x309f.html. Дата доступа: 20.02.2021.

5. Инновационный менеджмент: теория и практика / А. В. Марков [и др.] под науч. ред. А. В. Маркова. - Минск : «Колорград», 2015. - 513 с.

6. Конкурентоспособность в современной экономике: вызовы для региона ЕЭК ООН // Европейская Экономическая Комиссия ООН. - Женева, 2006. - 30 с.

7. Крупский, Д. М. Национальная инновационная система Беларуси: проблемы и перспективы развития: учебное пособие / Д. М. Крупский; «Институт парламентаризма и предпринимательства». - Минск, 2015. - 30 с.

8. Литовченко, С. Глобализация и конкурентоспособность: стратегии успеха / С. Литовченко, А. Дынин, П. Панов, А. Соколов. - М. : Ассоциация менеджеров, 2003. - 336 с.

9. Марков, А. В. Методы управления инновационной деятельностью на предприятии: учеб. пос. / А. В. Марков. - Минск : Колорград, 2020. -102 c.
10. Научные основы идентификации и использования общественнофункциональных инноваций / А. В. Марков [и др.]; под. ред. П. Г. Никитенко. - Мн. : «Право и экономика», 2004. - 399 с.

11. Создание условий, способствующих повышению конкурентоспособности и эффективности национальных инновационных систем // Европейская экономическая комиссия ООН. - Нью-Йорк и Женева, 2007. - 136 с.

\section{References}

1. Ansoff, I. Strategicheskij menedzhment. Klassicheskoe izdanie / I. Ansoff. - SPb.: Piter, 2011. - 344 s.

2. Golovachev, A. S. Formirovanie konkurentnyh strategij razvitiya predpriyatij. Ekonomika i upravlenie / A. S. Golovachev, M. A. Golovacheva. - № 2. - 2011. - S. 61-67.

3. Zashchita monopolii v teoriyah I. SHumpetera i D. K. Gelbrejta [EIektronnyj resurs]. - Rezhim dostupa: https://economyweb.org/?p=98. - Data dostupa: 20.02.2021.

4. Innovacionnost' kak faktor konkurentosposobnosti [Elektronny] resurs]. - Rezhim dostupa: https://infopedia.su/8x309f.html. - Data dostupa: 20.02.2021.

5. Innovacionnyj menedzhment: teoriya i praktika / A. V. Markov [i dr.]; pod nauch. red. A. V. Markova. - Minsk : «Kolorgrad», 2015. - 513 s.

6. Konkurentosposobnost' $v$ sovremennoj ekonomike: vyzovy dlya regiona EEK OON // Evropejskaya Ekonomicheskaya Komissiya OON. - ZHeneva, 2006. - $30 \mathrm{~s}$.

7. Krupskij, D. M. Nacional'naya innovacionnaya sistema Belarusi: problemy i perspektivy razvitiya: uchebnoe posobie / D. M. Krupskij; «Institut parlamentarizma i predprinimatel'stva». - Minsk, 2015. - $30 \mathrm{~s}$.

8. Litovchenko, S. Globalizaciya i konkurentosposobnost': strategii uspekha / S. Litovchenko, A. Dynin, P. Panov, A. Sokolov. - M. : Associaciya menedzherov, 2003. $-336 \mathrm{~s}$.

9. Markov, A. V. Metody upravleniya innovacionnoj deyatel'no-st'yu na predpriyatii: ucheb. pos. / A. V. Markov. - Minsk : Kolor-grad, 2020. $102 \mathrm{~s}$.

10. Nauchnye osnovy identifikacii i ispol'zovaniya obshchestvennofunkcional'nyh innovacij / A. V. Markov [i dr.]; pod. red. P. G. Nikitenko. - Mn. : «Pravo i ekonomika», 2004. - 399 s.

11. Sozdanie uslovij, sposobstvuyushchih povysheniyu konkurentosposobnosti i effektivnosti nacional'nyh innovacionnyh sistem // Evropejskaya ekonomicheskaya komissiya OON. - N'yu-Jork i ZHeneva, 2007. - $136 \mathrm{~s}$.

Материал поступил в редакцию 22.05.2021 